\title{
NUMERICAL SIMULATION BY MEANS OF FINITE ELEMENT METHOD OF PLASTIC DEFORMATION PROCESSES OF LIGHTWEIGHT METALLIC MATERIALS
}

\author{
GIRJOB Claudia \\ associate professor/ Ph.D., Faculty of Engineering./Department. Machines and Industrial Equipments, “Lucian \\ Blaga" University of Sibiu, Sibiu, Romania, claudia.girjob@ulbsibiu.ro
}

\begin{abstract}
The present paper aims to study the forming behavior of lightweight metallic materials in order to reduce the total weight of the vehicles without affecting their performances. For the theoretical and experimental researches, among the lightweight metallic materials, the AZ31B magnesium alloy has been chosen, a representative alloy for the magnesium-zinc-aluminium alloy system. The results of the theoretical researches, made on finite elements models, were validated by means of experimental researches consisting of tensile tests and forming limit curves determination tests.
\end{abstract}

Key words: AZ31B, FEM, lightweight metallic material, tensile test, forming limit curve

\section{Introduction}

The emphasis upon environmental protection within the last years lead to a rise in the interest of reducing the carbon dioxide emissions, which may be achieved mainly by reducing the energy consumption, and for product recycling among transportation equipments manufacturers. These objectives may be achieved by using light metallic materials for manufacturing various components, in order to reduce the total weight of the vehicles without affecting their performances.

Among low plasticity metallic materials, one may mention aluminium and magnesium alloys, which have densities much lower as other metallic materials, $1,74 \mathrm{~g} / \mathrm{cm}^{3}$ and 2,7 g/cm respectively. These alloys have the advantage of a good mechanical strength; have a good thermal conductibility and good shock damping properties. The great difficulty in using light materials is their low plasticity on the room temperature. Consequently, in the last period, researches regarding the determination of methods and techniques for improving the deformation behavior of light alloys were performed. The researches lead to the conclusion that by heating the light alloys work pieces, during the plastic deformation process, at temperatures between 200 and $300^{\circ} \mathrm{C}$, it is possible to obtain a considerable increase of heir plasticity. Thus, these alloys may be used for manufacturing parts in the automotive industry by means of various plastic deformation methods [1].

\section{Materials used in the researches}

The experimental researches were made in order to evaluate the forming capacity of low plasticity alloys. Among this category of materials, the AZ31B magnesium alloy has been chosen, alloy representative for magnesium-zinc-aluminum systems. The main advantage of this alloy is its very low density $(1,74 \mathrm{~g} / \mathrm{cm} 3)$, it is used for automotive industry and aeronautic industry parts, parts which have to have a reduced height. [1]

The chemical composition of the magnesium alloy AZ31B, in percent by mass, is shown in table 1.

Table 1 The chemical composition of the magnesium alloy AZ31B

\begin{tabular}{|c|c|c|c|c|c|}
\hline $\mathrm{AL}$ & $\mathrm{CU}$ & $\mathrm{ZN}$ & $\mathrm{MN}$ & SI & MG \\
\hline $3,0[\%]$ & $0,05[\%]$ & $1,0[\%]$ & $0,2[\%]$ & $0,1[\%]$ & Rest \\
\hline
\end{tabular}

The mechanical characteristics of the magnesium alloy AZ31B are presented in table 2 [2].

Table 2 The mechanical characteristics of the magnesium alloy AZ31B

\begin{tabular}{|l|c|}
\hline \multicolumn{1}{|c|}{ Mechanical characteristics } & Values \\
\hline Density $\left[\mathrm{kg} / \mathrm{mm}^{3}\right.$ ] & $1,74 \times 10^{-6}$ \\
\hline Young's modulus [GPa] & 45 \\
\hline
\end{tabular}




\begin{tabular}{|l|c|}
\hline Yield strength [MPa] & 150 \\
\hline Tensile strength [MPa] & 255 \\
\hline Elongation [\%] & 10 \\
\hline Anisotropy [-] & 1,91 \\
\hline Poisson coefficient [-] & 0,35 \\
\hline
\end{tabular}

3. Numerical simulation by means of finite element method of plastic deformation processes

The Abaqus/Explicit software was used for numerical simulation by means of finite element method (FEM) of plastic deformation processes of low plasticity materials.

For numerical simulation by means of FEM, two finite elements models have been made: a model for tensile test (fig. 1) and a model for the Nakajima test (fig. 2) [3].

The model made for numerical simulation of the tensile test aimed the check of the experimentally determined material properties: modulus of elasticity, hardening curve and anisotropy coefficients. The evaluation of the accuracy of the experimental results and the validation of the finite elements model has been achieved by comparing the values and distributions of main strains and the material thickness, theoretically and experimental determined. This evaluation has been made of the time period between the start of the test and the moment just before the necking localization appeared, due to the fact that it cannot be modeled using "shell-type" classic elements, because the size of the necking area is determined by the thickness of the element [4].

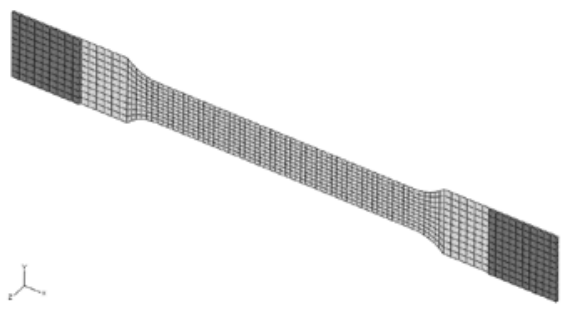

Figure 1: The model for numerical simulation of the tensile test

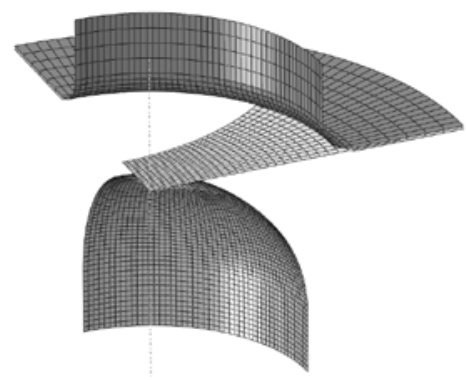

Figure 2: The parameterized finite elements model for the Nakajima test (ex. for $R=40 \mathrm{~mm}$ )

Thus, were evaluated: the values and distributions of the main strains $\varepsilon_{1}$ (fig. 3) and $\varepsilon_{2}$ (fig. 4), the values and distributions of the material thickness (for the theoretical results) respectively of the thickness reduction (for the experimental results) (fig. 5).
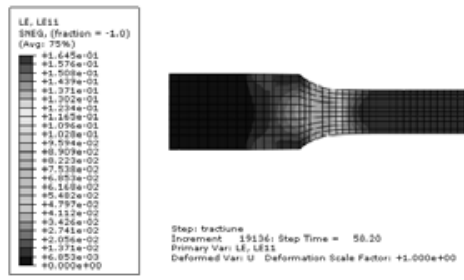

Numerical simulation
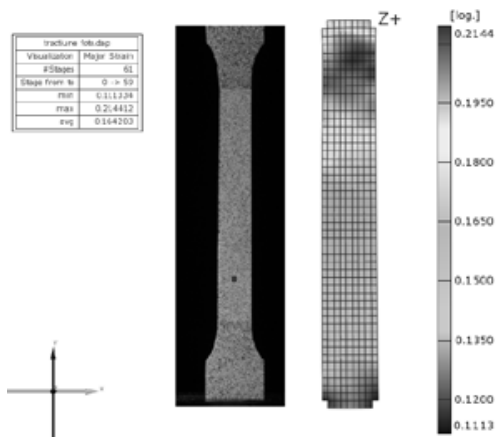

Experimental

Figure 3: Distribution of strain $\varepsilon_{1}$ 


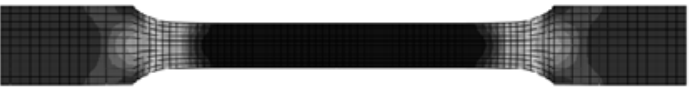

Numerical simulation
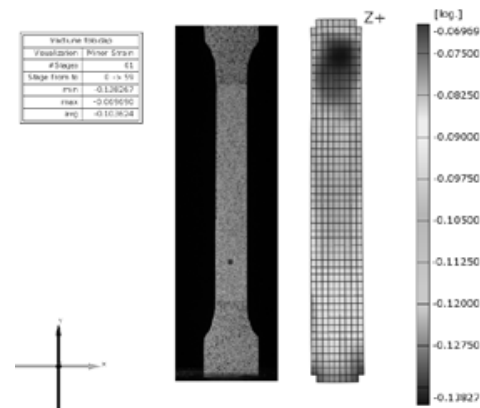

Figure 4: Distribution of strain $\varepsilon_{2}$
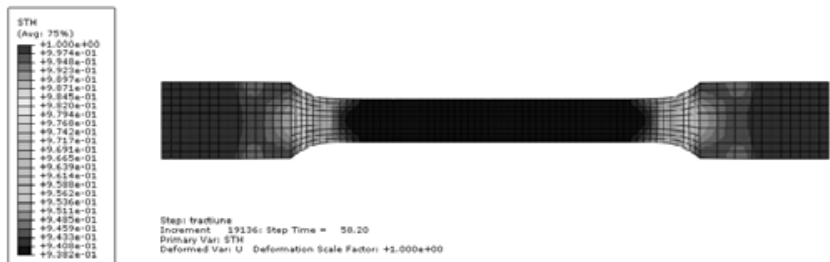

Numerical simulation
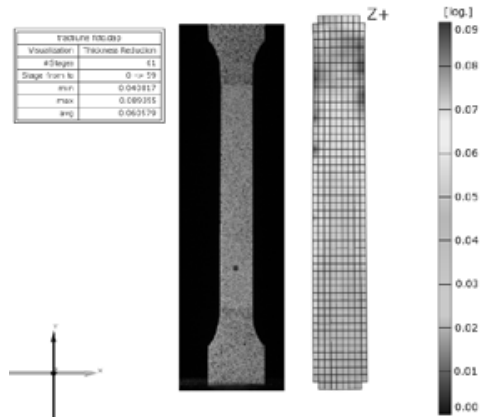

Figure 5: Distribution of the material thickness

If the average values are compared (noted as avg), the ones calculated by the strains optical measurement system Aramis, for the calibrated zone of the test sample, with the values obtain from numerical simulation for the same zone, it can be noticed that the results are very closed to each other: for the $\varepsilon_{1}$ strain: 0,1645 in the numerical simulation case, versus 0,1642 in the experimental case; for $\varepsilon_{2}$ strain : - 0,1029 in the numerical simulation case, versus $-0,1036$ in the experimental case; the thickness of the test sample it's $0,9382 \mathrm{~mm}$ in the numerical simulation case, versus $0,9394 \mathrm{~mm}$ in the experimental case (thickness reduction by $0,0606 \mathrm{~mm}$ ).

For the numerical simulation of the forming limit curves test by means of Nakajima method, a finite elements model has been made, parameterized depending on the cutting radius of the specimens. This model has been used for the comparative evaluation of the values and distributions of the limit strains, in the element's plane, theoretically and experimentally determined, in order to validate the material properties and the plastic deformation of low plasticity materials process parameters [5].

In order to compare the experimental results with the ones obtained by numerical simulation, the major strain distributions (fig. 6), minor strain distributions (fig. 7) and the variation of the thickness of the specimen (fig. 8), were analyzed.

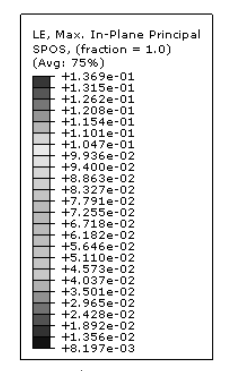

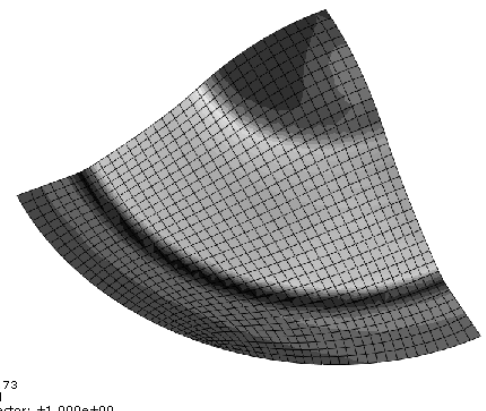

Numerical simulation

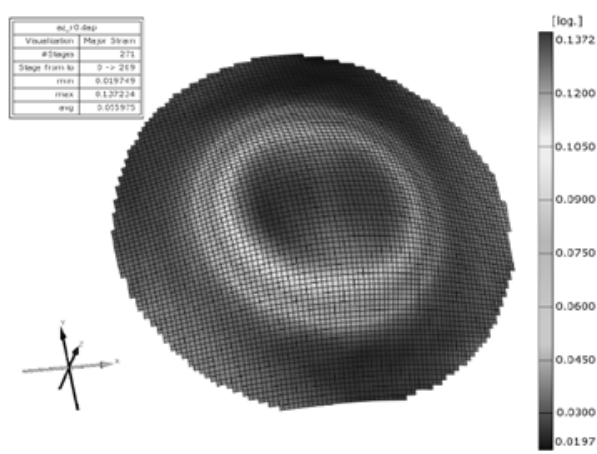

Experimental

Figure 6: Distribution of major strain $\varepsilon_{1}$ 


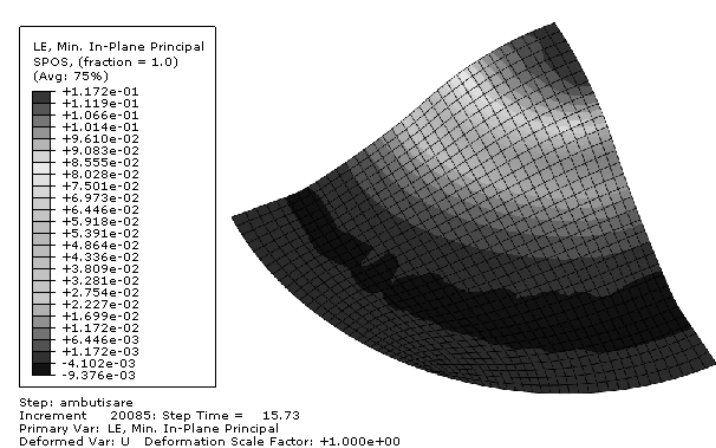

Numerical simulation

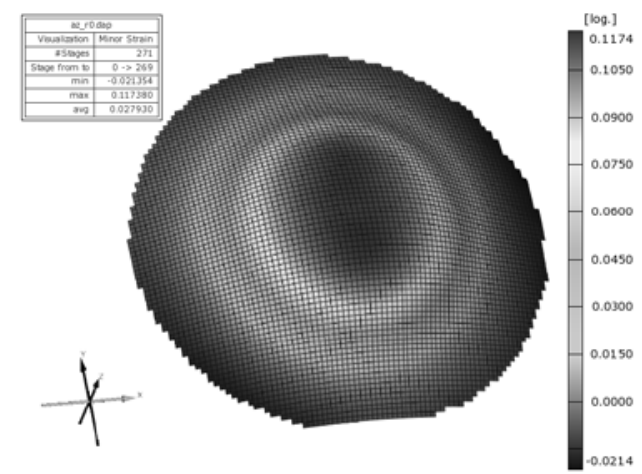

Experimental

Figure 7: Distribution of minor strain $\varepsilon_{2}$

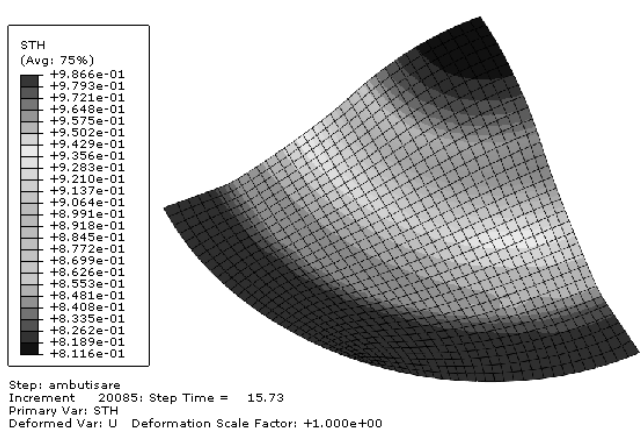

Numerical simulation

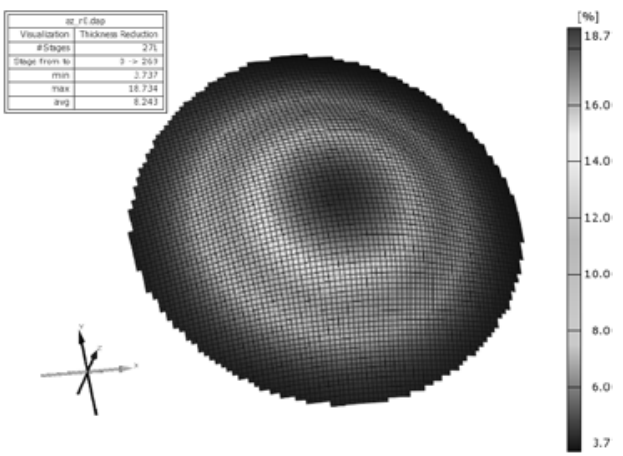

Experimental

Figure 8: : Distribution of the material thickness

In the case of the main strain $\varepsilon_{1}$ a similar distribution of the two types of researches it's noticed, the theoretical and the experimental ones. The maximum main strain are obtained in the pole zone, the results are 0,1369 in the numerical simulation case, versus 0,1372 in the experimental case. Those results reduce once the forming pole is gone.

The distribution of $\varepsilon_{2}$ strain is the same in the both case, determined thru numerical simulation, or the experimental one. The maximal values of these are obtained in the pole zone, the results are 0,1172 in the numerical simulation case, versus 0,1174 in the experimental case.

Regarding the thickness of the material, it can see that minimal thickness is reached in the forming pole zone, it's value is $0,8116 \mathrm{~mm}$ (the maximum reduction of the thickness it's 18,84, regarding the initial thickness level of the test tube, which is $1 \mathrm{~mm}$ ).

\section{Conclusions}

Based on the comparative analysis, experimental and numerical simulation, it may be concluded that the mechanical characteristics and the properties of the researched materials were determined with good accuracy and the parameterized finite elements model offers similar results to those obtained experimentally.

\section{Acknowledgment}

This work was supported by the strategic grant POSDRU/159/1.5/S/133255, Project ID 133255 (2014), co-financed by the European Social Fund within the Sectorial Operational Program Human Resources Development 2007-2013.

\section{References}

1. Kulekci M. K., Magnesium and its alloys applications in automotive industry, International Journal of Advanced Manufacturing Technology, Springer-Verlag, London, Volume 39, Issue 9-10, (2007) pp 851-865

2. Ambrogio G., Bruni C., Bruschi S., Filice L., Ghiotti A., Simoncini M., Characterization of AZ31B magnesium alloy formability in worming conditions, The International Journal of Material Forming, Springer/ESAFORM, Volume 1, Issue 1 Supplement (2008) pp 205-208/

3. Girjob C., Bologa O., Racz G., Biris C. Experimental Research of the Formability of Lightweight Metallic Materials Used in Automotive Industry, Applied Mechanics and Materials Vol 760 (2015) pp 391-396

4. Chalal H., Racz S.G., Balan T., Springback of thick sheet AHSS subject to bending under tension International Journal of Mechanical Sciences - Vol. 59, $n^{\circ} 1, p .104-114$, (2012)

5. Breaz, R., Researches and contributions regarding the accuracy of machine-tools and errors compensation techniques, doctoral thesis, Technical University of Cluj-Napoca, (2001) 